\title{
Plasma Zinc Levels, Lipid Profile Parameters and CVD Risk Markers in Relation to Glycemic Status in T2 DM Patients
}

\author{
Aman James ${ }^{1}$, Nagendra $\mathrm{S}^{2}$, Lata Telang ${ }^{3}$, Kashinath $\mathrm{RT}^{4}$ \\ ${ }^{1}$ Intern, Dept. of Medicine, ${ }^{2}$ Chairperson Subbaiah Research Center, ${ }^{3}$ Professor, Dept. of Medicine, ${ }^{4}$ Director, \\ Research \& Development Department, Subbaiah Institute of Medical Sciences, Purle, Shivamogga.
}

Corresponding Author: Kashinath R T

\begin{abstract}
Background: Diabetes is global endemic rapidly increasing in both developed and developing countries and is a common secondary cause of hyperlipidaemia in T2DM patients. Diabetic- dyslipidemic patients exhibit atherogenic lipid profile, which greatly increases their CVD risk. Zinc, essential trace element, has significant function in energy metabolism and has been shown to serve a regulatory role in insulin signalling pathway and in supporting structural integrity of endothelial cells. A study designed to assess the plasma zinc status in $\mathrm{t} 2 \mathrm{dm}$ patients and to correlate zinc levels with lipid parameters, CVD markers as well as with glycemic status.
\end{abstract}

Methods: The $\mathrm{t} 2 \mathrm{dm}$ patients in the age group 30-60 years were randomly selected and were sub-grouped age wise, glycemic status-wise and diabetic duration-wise. Fasting Glucose, lipid parameters and zinc were estimated and atherogenic Index of Plasma (AIP), Atherogenic Coefficient (AC), and Cardiac Risk Ratio (CRR) were calculated.

Results: The results shows levels of glucose, lipid parameters, AIP, AC and CRR are significantly elevated whereas the levels of HDLC and zinc are significantly lowered in t $2 \mathrm{dm}$ patients and the rises as well as the fall in HDLC and zinc are proportional to glycemic status.

Conclusion: It can be concluded from the present study that zinc levels are lower in $\mathrm{t} 2 \mathrm{dm}$ patients and is reciprocally related to glycemic status as well as to the diabetic duration. Further the rise in CVD markers is directly proportional to the glycemic status but inversely related to CVD markers.
Keywords: t2dm, CVD markers, glycemic status, zinc

\section{INTRODUCTION}

Zinc $(\mathrm{Zn})$ is a micro nutrient that serves as co-factor for synthesis, storage, stability and secretion of insulin by pancreas as well as it accounts for the conformation integrity of insulin in its hexametric crystalline form ${ }^{(1,2)}$. It also involved in the regulation of insulin receptor-initiated signal transduction mechanism and insulin receptor synthesis. Also $\mathrm{Zn}$ acts as a cofactor for the function of intracellular enzymes that may be involved in protein, lipid and glucose metabolism or participate as an integral component of several antioxidant enzymes. Zinc has an important role in the glucose utilization by muscle and fat cells ${ }^{3,4}$. Zinc is involved in glucose utilization and is known to stimulate glycolysis specifically glycolytic enzymes phasphofructo kinase and pyruvate kinase ${ }^{5,6}$ Further it has been observed that low serum zinc levels are associated with high cholesterol, triglycerides, and LDL levels ${ }^{7}$ Consistent hyperglycaemia and poor glycemic control may lead to life threatening micro and macro vascular complications in $\mathrm{t} 2 \mathrm{dm}$ patients. ${ }^{8,9}$ Many lipid profile parameters derived cardiac markers helps to assess the cardiac involvement in $\mathrm{t} 2 \mathrm{dm}$ patients.

Hence a study has been planned to assess the plasma zinc status in $\mathrm{t} 2 \mathrm{dm}$ patients and to correlate zinc levels with 
lipid profile parameters derived CVD markers as well as with glycemic status in t2dm patients.

\section{AIM \& OBJECTIVES}

To evaluate the significance of lipid profile parameters, CVD risk markers as well as plasma zinc levels in relation to glycemic status in $\mathrm{t} 2 \mathrm{dm}$ patients. To study plasma zinc levels, lipid profile parameters and $\mathrm{HbA} 1 \mathrm{c}$ in $\mathrm{t} 2 \mathrm{dm}$ patients and to correlate their relationship.

\section{MATERIALS \& METHODS}

This observational comparative study was undertaken at Research and Development Department, Subbaiah Institute of Medical Sciences (SuIMS) during the period of March 2020 to July 2021. The ethical clearance for the present work was procured from institutional ethics committee after successful presentation.

\section{Normal control subjects}

Normal, non-diabetic subjects in the age group of 30-60 years were be taken from the employees of SuIMS and its affiliated hospitals, Shivamogga.

\section{T2 DM Patients}

The $\mathrm{t} 2 \mathrm{dm}$ patients attending Medical Out Patient Department (OPD) of SuIMS, Shivamogga and its affiliated hospitals, in the age group 30- 60 years of age were randomly selected. A history regarding the illness was collected from these patients. Diabetic patients below the age of 30 years, those with psychiatric disorders as well as the patients receiving hormone therapy were excluded from the study.

\section{Grouping}

The study consists of a total number of 160 subjects with 80 normal control subjects and $80 \mathrm{t} 2 \mathrm{dm}$ patients. The selected t2 dm patients were sub-grouped age wise (30-40 years, $41-50$ years, $51-60$ years and above 61 years) and also sub- grouped depending on their glycemic status (based on HbA1c levels) as Good Glycemic Control Group, (HbA1c < 6.5\%), Fair Glycemic Control Group (HbA1c 6.5\% $7.9 \%$ ) and Poor Glycemic Control Group (HbA1c $<8.0 \%)$. The $\mathrm{t} 2 \mathrm{dm}$ patients were selected in such a way that each sub-group in $\mathrm{t} 2 \mathrm{dm}$ patients must have minimum 20 patients. The sub group division as well as number of patients included in each subgroup is given in chart-1.

CHART-1

\begin{tabular}{|l|l|l|}
\hline GROUP & DESCRIPTION & NUMBER OF SUBJECTS \\
\hline GROUP - N & NORMAL,NON DIABETIC GROUP & 80 \\
\hline GROUP - D & T2 DM PATIENTS & 80 \\
\hline GROUP - D1 & T2 DM - 31-40 Years & 20 \\
\hline GROUP - D2 & T2 DM - 41-50 Years & 20 \\
\hline GROUP - D3 & T2 DM - 51-60 Years & 20 \\
\hline GROUP - D4 & T2 DM - Above 61 Years & 20 \\
\hline GROUP - D5 & T2 DM - GOOD GLYCEMIC CONTROL ( HbA1C < 6.5\% ) & 30 \\
\hline GROUP - D6 & T2 DM - FAIR GLYCEMIC CONTR ( HbA1C < 6.5-7.9 \%) & 25 \\
\hline GROUP - D7 & T2 DM - POOR GLYCEMIC CONTROL ( HbA1C < 8.0\% ) & 25 \\
\hline Chart showing the division of t2dm patient age wise as well as glycemic status wise \\
\hline
\end{tabular}

\section{Sample Collection}

A fasting heparinised blood sample (5-6 ml) was collected from both $\mathrm{t} 2 \mathrm{dm}$ patients and from normal control subjects after obtaining a written Informed Consent from each one of them.

\section{Methods:-}

The samples were be centrifuged at $3000 \mathrm{rpm}$ for $6-8 \mathrm{~min}$ and the separated plasma was employed for the estimation of Fasting Plasma Glucose (FPG) ${ }^{10}$, Total Cholesterol (TC), Triglyceride (TG), HDL cholesterol (HDLC) ${ }^{11-13}$ and zinc levels ${ }^{14 .}$ LDL cholesterol, VLDL cholesterol, Atherogenic Index of Plasma (AIP), Atherogenic Coefficient (AC), and Cardiac Risk Ratio (CRR) were calculated using the fallowing standard relations. ${ }^{15-18}$

- $\mathrm{VLDLC}=(\mathrm{TAG} / 5)$ 
- $\mathrm{LDLC}=(\mathrm{TC}-\mathrm{HDLC}-\mathrm{VLDLC})$

- $\mathrm{CRR}=(\mathrm{TC} / \mathrm{HDLC})$

- $\mathrm{AIP}=\log (\mathrm{TAG} / \mathrm{HDLC})$

- $\mathrm{AC}=(\mathrm{TC}-\mathrm{HDLC} / \mathrm{HDLC})$

\section{STATISTICAL ANALYSIS}

The data obtained was statistically analysed using SPSS version 16 Software. Student " $\mathrm{t}$ " test was used to ascertain the significance and the level $\mathrm{p}<0.05$ was considered significant. The group $\mathrm{D}$ is compared with group $\mathrm{N}$ as well as the diabetic sub-groups are compared among each other to evaluate the significance.

\section{RESULTS}

The results obtained in the present study are depicted in Table 1, Table2, and Table 3 and in Figure 1 and 2.

\begin{tabular}{|c|c|c|}
\hline \multicolumn{3}{|c|}{ Table 1} \\
\hline & $\begin{array}{l}\text { GROUP-N } \\
\text { (NORMAL SUBJECTS) } \\
(80)\end{array}$ & $\begin{array}{l}\text { GROUP - D } \\
\text { (T2 dm PATIENT) } \\
(80)\end{array}$ \\
\hline FPG & $78.80 \pm 17.3$ & $220.92 \pm 22.80^{* * * *}$ \\
\hline TC & $172.8 \pm 28.6$ & $230.6 \pm 25.8 * * *$ \\
\hline TG & $110 \pm 26.82$ & $207.62 \pm 10.82 * * *$ \\
\hline HDLC & $51.2 \pm 9.6$ & $31.9 \pm 10.4^{* * *}$ \\
\hline LDLC & $110.8 \pm 20.4$ & $170.92 \pm 14.38 * * *$ \\
\hline VLDLC & $29.42 \pm 8.18$ & $42.43 \pm 9.10^{* * *}$ \\
\hline AIP & $0.513 \pm 0.02$ & $0.74 \pm 0.08 * * *$ \\
\hline $\mathbf{A C}$ & $2.21 \pm 0.53$ & $6.16 \pm 1.58 * * *$ \\
\hline CRR & $3.12 \pm 0.60$ & $6.88 \pm 0.66^{* * * *}$ \\
\hline HbA1c & $5.38 \pm 1.22$ & $7.82 \pm 0.52 * * *$ \\
\hline ZINC & $186.96 \pm 24.20$ & $92.29 \pm 18.70^{* * * *}$ \\
\hline \multicolumn{3}{|c|}{$\begin{array}{l}\text { Table showing plasma levels of fasting glucose (FPG), total } \\
\text { cholesterol (TC), Triglyceride (TG), HDL Cholesterol (HDLC), } \\
\text { LDL Cholesterol (LDLC), VLDL Cholesterol (VLDLC), } \\
\text { Atherogenic Index of Plasma (AIP), Atherogenic coefficient } \\
\text { (AC), Cardiac risk Ratio (CRR), HbAlc and Zinc in normal non- } \\
\text { diabetic subjects (Group N) and in T2DM patients (Group D). }\end{array}$} \\
\hline \multicolumn{3}{|c|}{$\begin{array}{l}\text { Note: } \\
\text { 1. The values are expressed as their Mean } \pm \text { SD. } \\
\text { 2. The number in parentheses indicates the number of subjects. } \\
\text { 3. Probability } * p>0.05, * * p>0.01 \text { and } * * * p>0.001 \text {. }\end{array}$} \\
\hline
\end{tabular}

Table 1 shows plasma levels of fasting plasma glucose (FPG), Total Cholesterol (TC), Triglyceride (TG), HDL Cholesterol (HDLC) LDL Cholesterol (LDLC), VLDL Cholesterol (VLDLC), Atherogenic Index Plasma (AIP), Atherogenic Coefficient (AC), Cardiac Risk Ratio (CRR), HbA1c and Zinc in normal non diabetic subjects (group-N) and in $\mathrm{t} 2$ $\mathrm{dm}$ patients (group-D). It is evident from the table that the levels of FPG, TC, TG, LDLC,
VLDLC, AIP, AC and CRR are significantly elevated $(p<0.001)$ in $t 2 \mathrm{dm}$ patients (group D) as compared to normal non diabetic subjects (group-N) whereas the levels of HDLC and zinc are Significantly lowered $(p<001)$ in group D as compared to group N. Further it is evident from the table that there is a proportionate decrease in plasma zinc levels along with an increase in CVD markers in indicating there is a close relationship between zinc and CVD risk in t2 $\mathrm{dm}$ patients.

Table 2 gives the plasma levels of FPG, TC, TG, HDLC, LDLC, VLDLC, AIP, AC, CRR, HbA1C and Zinc levels in age wise sub-grouped ( D1 - 31-40 years, group D2-41-50 years, group D3 51-60 years and group D4- above 61 years ) $\mathrm{t} 2 \mathrm{dm}$ patients. Group D1 is compared with group D2, D3 and D4, group D2 is compared with group D3 and D4 where as group D3 is compared with group D4. It is seen from the table that there is a proportionate fall in zinc levels along with a rise in CVD markers AIP, AC and CRR in group D1, D2 and D3 suggesting that there is a close relationship between CVD markers and plasma zinc levels in age wise-sub grouped $\mathbf{t} 2 \mathrm{dm}$ patients. Further it is seen that the elevation in CVD markers is directly proportional to somatic age of t2dm patient where as the fall in zinc levels is inversely proportional.

Table -3 shows plasma levels of FPG, TC, TG, HDLC, LDLC, VLDLC, AIP, AC, CRR HbA1c and Zinc in $\mathrm{t}-2 \mathrm{dm}$ patients sub-grouped according to their glycemic control (Group D5, D6, D7). Group D5 is compared with group D6 and D7 where as group D6 is compared with group D7. It is clear from the table that plasma levels of TC, TG, LDLC, VLDLC, AIP, AC, CRR and HbA1c are proportionately elevated $(\mathbf{p}<0.001)$ in group D5,group D6 and group D7 along with HbA1c levels where as the levels of HDLC and zinc are proportionately lowered $(\mathbf{p}<0.001)$ in these groups. 
Aman James et.al. Plasma zinc levels, lipid profile parameters and CVD risk markers in relation to glycemic status in T2 DM patients.

\begin{tabular}{|c|c|c|c|c|c|c|}
\hline \multicolumn{7}{|c|}{$T A B L E-2$} \\
\hline & & $\begin{array}{l}\text { Group D1 } \\
(30-40) \\
(20)\end{array}$ & $\begin{array}{l}\text { Group D2 } \\
(41-50) \\
(20)\end{array}$ & $\begin{array}{l}\text { Group D3 } \\
(51-60) \\
(20)\end{array}$ & $\begin{array}{l}\text { Group D4 } \\
\text { (above 60) } \\
\text { (20) }\end{array}$ & \\
\hline & FPG & $180.80 \pm 16.80$ & $225.50 \pm 28.50^{* * *}$ & $268.60 \pm 20.80^{* *}$ & $242.40 \pm 18.80 * * *$ & \\
\hline & TC & $192.60 \pm 18.60$ & $220.80 \pm 18.60$ & $262.60 \pm 20.60$ & $268.40 \pm 16.20 * * * \alpha \alpha$ & \\
\hline & TG & $160.60 \pm 10.80$ & $186.40 \pm 16.60$ & $182.60 \pm 8.80$ & $210.20 \pm 16.90 * * * \beta$ & \\
\hline & HDLC & $38.60 \pm 6.10$ & $32.80 \pm 8.80$ & $29.80 \pm 9.20$ & $26.80 \pm 6.60$ & \\
\hline & LDLC & $121.80 \pm 8.20$ & $136.90 \pm 8.90$ & $186.80 \pm 10.10 * * \alpha \alpha$ & $201.60 \pm 11.80 * * * \alpha \alpha \alpha$ & \\
\hline & VLDLC & $32.12 \pm 3.50$ & $37.9 \pm 4.80$ & $36.7 \pm 6.9$ & $32.8 \pm 11.2$ & \\
\hline & AIP & $0.620 \pm 0.05$ & $0.850 \pm 0.06^{* * *}$ & $0.820 \pm 0.03 * *$ & $0.880 \pm 0.05 * * * \alpha \alpha \beta \beta$ & \\
\hline & $\mathbf{A C}$ & $0.584 \pm 0.09$ & $0.730 \pm 0.08 * * *$ & $0.687 \pm 0.060^{* *}$ & $0.805 \pm 0.092 * * * \alpha \alpha \beta \beta$ & \\
\hline & CRR & $4.98 \pm 1.02$ & $6.19 \pm 0.90$ & $8.60 \pm 0.80 * * \alpha \alpha$ & $8.98 \pm 0.52 * * * \alpha \alpha \alpha$ & \\
\hline & HbA1c & $8.14 \pm 1.78$ & $7.20 \pm 0.46$ & $8.68 \pm 0.78 \alpha$ & $8.27 \pm 0.92$ & \\
\hline & ZINC & $182.80 \pm 16.60$ & $176.30 \pm 18.60$ & $128.80 \pm 16.80^{* * *} \alpha \alpha$ & $98.20 \pm 12.10^{* * * *} \alpha \alpha \alpha \beta \beta \beta$ & \\
\hline \multicolumn{7}{|c|}{$\begin{array}{l}\text { Table showing plasma level of } F P G, T C, T G, H D L C, L D L C, V L D L C, A I P, A C, C R R, H b A 1 c \text { and Zinc in age wise sub grouped } t-2 \text { dm } \\
\text { patients (group D1, D2, D3 and D4). }\end{array}$} \\
\hline \multicolumn{7}{|c|}{$\begin{array}{l}\text { Note: } \\
\text { 1. The values are expressed as their Mean } \pm S D \text {. } \\
\text { 2. The number in parentheses indicates the number of subjects. } \\
\text { 3. Probability } * / \alpha / \beta p>0.05, * * / \alpha \alpha / \beta \beta p>0.01 \text { and } * * * / \alpha \alpha \alpha / \beta \beta \beta p>0.001 \text {. } \\
\text { 4. Comparison of group D1 with } D 2, D 3 \text { and } D 4 \text {-represented by } * \\
\text { 5. Comparison of group D2 with } D 3, D 3 \text { and } D 4 \text { - represented by } \alpha \\
\text { 6. Comparison of group } D 3 \text { with } D 4-\text { represented by } \beta\end{array}$} \\
\hline
\end{tabular}

Table-3

\begin{tabular}{|c|c|c|c|c|c|}
\hline & & $\begin{array}{l}\text { Group D-5 } \\
(\text { HbA1c }<6.5) \\
(30)\end{array}$ & $\begin{array}{l}\text { Group D- } 6 \\
\text { (HbA1C 6.5-7.9) } \\
(25)\end{array}$ & $\begin{array}{l}\text { Group D -7 } \\
(\text { HbA1c }>8) \\
(25)\end{array}$ & \\
\hline & FPG & $210.60 \pm 18.20$ & $248.48 \pm 18.80$ & $258.60 \pm 22.20 * * *$ & \\
\hline & TC & $220.50 \pm 15.20$ & $252.40 \pm 20.10$ & $268.70 \pm 12.20^{* * * *}$ & \\
\hline & TG & $140.80 \pm 10.20$ & $156.40 \pm 9.80$ & $190.60 \pm 8.20 * * * \alpha \alpha$ & \\
\hline & HDLC & $40.60 \pm 8.80$ & $30.50 \pm 7.60$ & $26.60 \pm 8.20 * * *$ & \\
\hline & LDLC & $142.60 \pm 22.20$ & $187.60 \pm 16.80$ & $204.40 \pm 12.60^{* * *}$ & \\
\hline & VLDLC & $28.20 \pm 4.20$ & $31.60 \pm 4.20$ & $38.50 \pm 6.20^{* *}$ & \\
\hline & AIP & $0.540 \pm 0.040$ & $0.660 \pm 0.040$ & $0.860 \pm 0.030 * * * \alpha \alpha$ & \\
\hline & $\mathbf{A C}$ & $3.60 \pm 0.60$ & $4.20 \pm 0.60$ & $6.80 \pm 0.90 * * * \alpha \alpha$ & \\
\hline & CRR & $3.40 \pm 0.40$ & $5.80 \pm 0.80$ & $8.32 \pm 0.72 * * *$ & \\
\hline & HbA1c & $5.73 \pm 0.08$ & $7.03 \pm 0.06$ & $9.40 \pm 0.92 * * *$ & \\
\hline & ZINC & $81.96 \pm 12.50$ & $80.60 \pm 8.80$ & $66.67 \pm 7.90^{* * * *} \alpha$ & \\
\hline \multicolumn{6}{|c|}{$\begin{array}{l}\text { Table showing plasma levels of FPG, TC, TG, HDLC, LDLC, VLDLC, AIP,AC, CRR HbAlc and Zinc levels in t-2 dm patients sub } \\
\text { grouped according to their glycemic status (Group D5, Group D6, Group D7). }\end{array}$} \\
\hline \multicolumn{6}{|c|}{$\begin{array}{l}\text { Note: } \\
\text { 1. The values are expressed as their Mean } \pm S D \text {. } \\
\text { 2. The number in parentheses indicates the number of subjects. } \\
\text { 3. Probability } * / \alpha p>0.05, * * / \alpha \alpha / p>0.01 \text { and } * * * / \alpha \alpha \alpha p>0.001 \text {. } \\
\text { 4. Comparison of group } D 5 \text { with } D 6 \text { and } D 7 \text { - represented by * } \\
\text { 5. Comparison of group } D 6 \text { with } D 7, D 3-\text { represented by } \alpha\end{array}$} \\
\hline
\end{tabular}

Figure 1 and 2 gives the comparative bar graph of zinc and CVD markers in group N, Group D. and in t2dm sub-groups D5, D6 and D7

Figure 1 a narrates the comparative bar graphs of plasma Zinc levels in normal non diabetic subjects (Group N) and in T2 DM subjects (Group D). It is evident from the figure that plasma Zinc levels are significantly $(p<0.001)$ lowered in Group D as compared to Group $\mathrm{N}$ suggesting a deficiency of zinc in T2 DM patients.

Figure $1 \mathrm{~b}$ gives the comparative bar graphs of CVD risk Indicators (AIP, AC, CRR) and HbA1c in Group N and group D. it is evident from the graph that there is a significant raised $(p<0.001)$ along with HbAlc (glycaemic control index) in group $\mathrm{D}$ as compared to group $\mathrm{N}$ indicating rise in CVD markers in T2 DM patients is proportional to degree of glycaemic control.

Figure $2 \mathrm{a}$ and $2 \mathrm{~b}$ gives the comparative bar graphs of zinc (figure 2a) and CVD markers (figure 2b) in glycaemic status- wise sub- grouped t2dm patients group D5, D6 and D7. It is seen from the graph zinc levels are proportionately lowered in group D5, D6 and D7 as well as CVD markers are proportionately rised in group D5, D6 and D7 in t2dm patients. Further it is evident from figure 4 that the rise in CVD markers (AIP, AC, CRR) is 
Aman James et.al. Plasma zinc levels, lipid profile parameters and CVD risk markers in relation to glycemic status in T2 DM patients.

proportional to glycaemic status in these patients.

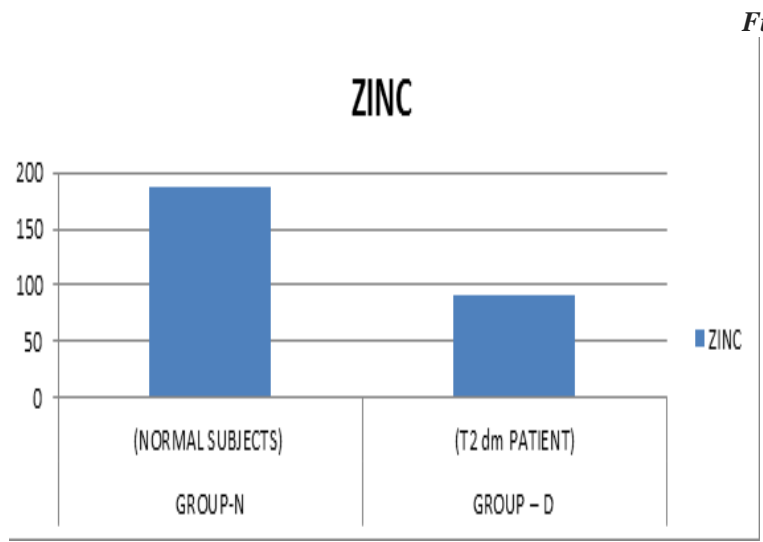

Figure 1a: Graph showing relation between zinc levels in nondiabetic subjects (group $n$ ) vs. in diabetic patients (group - D).

Figure:1

\section{ZINC}

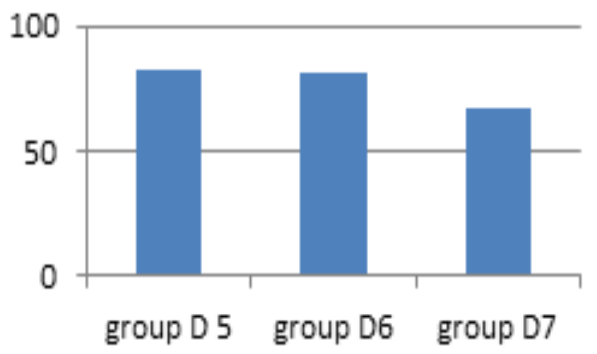

Figure 2a: Graph showing plasma zinc level in Group D5, D6, and $D 7$ in diabetic groups.

\section{DISCUSSION}

Diabetes is now considered as a global endemic with rapidly increasing prevalence both in developed and in developing countries ${ }^{19}$ and is a group of metabolic disease characterized by hyperglycaemia resulting from defects in insulin secretion, insulin action or both. Uncontrolled diabetic patients are characterized by hyperglycaemia, hyper insulinemia, hyper protein glycation and raised oxidative stress which cause early appearance of diabetic complications 20 leading to failure of various organs, especially the eyes, kidneys, nerves, heart and blood vessels ${ }^{21}$ resulting in diabetic complication like retinopathy, nephropathy, neuropathy and cardiopathy, making t $2 \mathrm{dm}$ patients highly vulnerable group for cardiovascular diseases (CVD) threat.

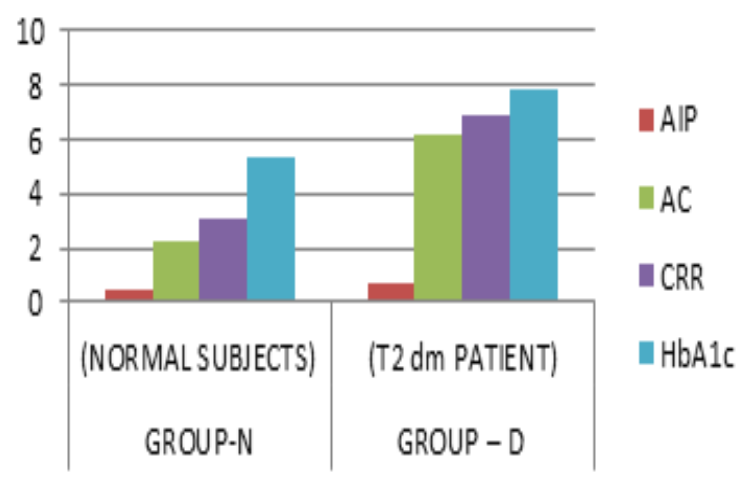

Figure 1b: Graph showing relationship between cardiac risk indicators and HbAlc levels in non-diabetic patients and diabetic patients.

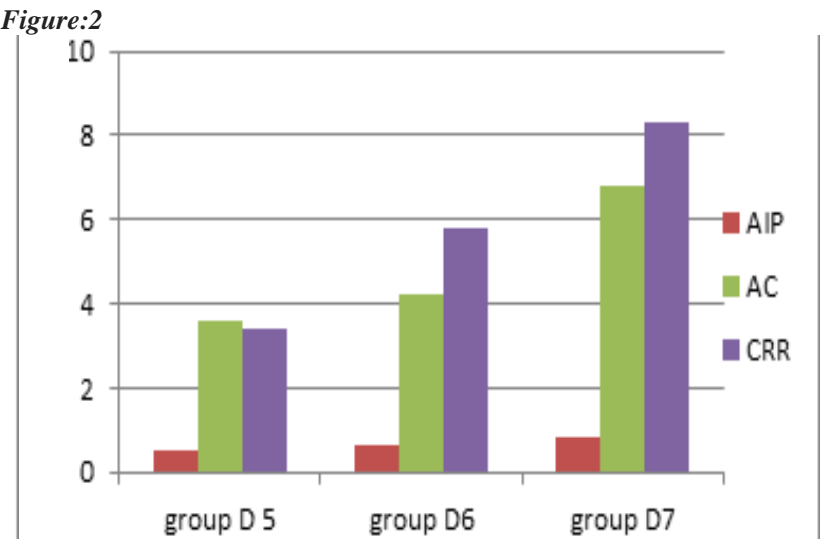

Figure 2b: Graph showing CVD risk indicator with respect to glycaemic status (HbAlc) in diabetic patients.

Lowered glucose utilization, raised fat turnover and fat utilization due to sub normal functions of insulin as insulin is known to influence not only glucose metabolism but also fat metabolism ${ }^{22}$ results in diabetic dyslipidemia which is characterized by an atherogenic lipid profile with raised total cholesterol, LDL cholesterol and a lowered HDL cholesterol level which increases their risk for CVD ${ }^{23}$. The results of the present study given in table 1 clearly establishes the $\mathrm{t} 2 \mathrm{dm}$ patients are under CVD risk, Further the CVD risk in these $\mathrm{t} 2 \mathrm{dm}$ patients is proportional to their somatic age (ref table 2) as well as to their glycemic status (ref table 3 ) indicating that aging and poor glycemic status has a positive effect on their CVD risk probability. This is further evidenced by the results shown in table 3 and figure 3 that there is a parallel relationship of CVD 
markers - AIP, AC and CRR along with glycemic status of $\mathrm{t} 2 \mathrm{dm}$ patients indicating strong relationship between lipid profile parameters, glycemic status and Cardio Vascular Diseases ${ }^{24}$

Zinc, an essential micro - nutrient with anti-oxidant activity, has been shown having a significant role in glucose utilization as well as in insulin action ${ }^{25}$. It is observed by many researchers that the plasma zinc levels are lower in $\mathrm{t} 2 \mathrm{dm}$ patients ${ }^{26-28}$ and zinc supplementation has a beneficial effect ${ }^{29}$. It is seen from the table1 that $\mathrm{t} 2 \mathrm{dm}$ patients are heaving significantly lower zinc levels compared to normal non diabetic counter parts which is in agreement with earlier studies ${ }^{30-32}$. Further it is seen that the plasma zinc levels in $\mathrm{t} 2 \mathrm{dm}$ patients progressively decreases over the age (ref table2) and there is a proportionate fall in zinc levels with increasing $\mathrm{HbAlc}$ levels indicating that is a reciprocal fall in the zinc levels with glycemic status, that is, poorer the glycemic status the lower is the plasma zinc levels (ref table3 and fig-2). Zinc is involved in glucose utilization and is known to stimulate glycolysis as well as glycolytic enzyme - phasphofructo kinase and pyruvate kinase $(5,6)$ hence a lowered zinc level may lower glucose utilization thus may cause hyperglycemia. The present studies with $\mathrm{t} 2 \mathrm{dm}$ patients further indicates that a significant rise in CVD markers and a significant fall in plasma zinc levels which is in proportional to rise in $\mathrm{HbA1c}$ levels suggesting poorer the glycemic status lower is the zinc levels and higher in the levels of CVD markers, AIP, AC and CRR.

\section{CONCLUSION}

It can be concluded from the present study with $\mathrm{t} 2 \mathrm{dm}$ patients that the plasma zinc levels are lower in t2dm patients and is reciprocally related to glycemic status as well as to the diabetic duration. Further the rise in CVD markers- AIP, AC, CRR, directly proportional to the glycemic status of the patients where as a reciprocal proportion is seen with plasma zinc levels. Hence the present study suggests a zinc supplementation may help in improving glycemic status as well as to reduce the cardio vascular risk. However a further study with zinc supplementation, in varying doses, may throw much light on these findings.

\section{Acknowledgement: None}

Conflict of Interest: None

\section{Source of Funding: None}

\section{Ethical Approval: Approved}

\section{REFERENCES}

1. Dunn MF (2005) Zinc-ligand interactions modulate assembly and stability of the insulin hexamer-A review. Biometals 18: 295-303.

2. Kimura T, Kambe T (2016) The Functions of Metallothionein and ZIP and ZnT Transporters: An Overview and Perspective. Int J Mol Sci17: 336.

3. Anderson RA, Roussel AM, Zouari N, Mahjoub S, Matheau JM, et al. (2001) Potential antioxidant effects of zinc and chromium supplementation in people with type 2 diabetes mellitus. J Am Coll Nutr 20: 212-218.

4. Cruz KJ, de Oliveira AR, Marreiro DN (2015) Antioxidant role of zinc in diabetes mellitus. World J Diabetes 6: 333-337.

5. Canesi L, Betti M, Ciacci C, Gallo G. Insulin-like effect of zinc in mytilus digestive gland cells: modulation of tyrosine kinase-mediated cell signaling. Gen Comp Endocrinol. 2001;122(1):6066.

6. Tamaki N, Ikeda T, Funatsuka A. Zinc as activating cation for muscle glycolysis. J Nutr Sci Vitaminol. 1983;29(6):655-62.

7. Muhammad Farooq Zinc deficiency is associated with poor glycemic control. Journal of college of physician and surgeons Pakistan 2019, vol. 29 (3): 253257.

8. Arsheg D Mooradian. Cardio Vascular disease in type2 diabetus mellitus: current management Arch.intern.med.2003,163(1),33-40 
9. Marakku Laakso. Hyperglycaemia and cardio vascular disease in typeII diabetus. Diabetes.1999,48(5),937-42

10. Richard J.Henry, Donald,C.Connan and James Winkelman(1974). Clinical Chemistry; II Edition, 1974 Harper row Publishers NY,Chapter $\quad-25$ Carbohydrates, pp 1285-1289.

11. Naito HK. Coronary artery disease and disorders of lipid metabolism: Clinical chemistry theory analysis co relations. 4th ed. Kaplan LA, Peace AJ Kazmierczak SC, eds. St Louis, USA: Mosby Inc;2003: 603.

12. Tietz NW. Clinical guide to laboratory tests. WB Saunders Co; 1995: 4.

13. Matsuzaki Y, Kawaguchi E, Morita Y, Mashige F,Ohisa S, Nakahara K. Evaluation of two kinds of reagents for direct determination of HDLcholesterol. J Anal Bio-Sc.1996;19:419-7.

14. Tetsuo-Makino (1991) Colorimetric determination of zinc, Chimica Clinica. Acta. 197:209-220

15. Friedwal WT, Levy R1, Fredrickson DS. Estimation of the concentration of lowdensity lipoprotein cholesterol in plasma, without use of the preparative ultracentrifuge. Clin Chem. 1972;18(6): 499-502.

16. Ikewuchi $\mathrm{Cj}$, Ikewuchi CC. Alteration of plasma lipid profile and atherogenic indices of cholesterol loaded rats by Tridax procumbencens Linn: Imlications for the management of obesity and cardiovascular diseases. Biokemistri. 2009; 21(2):95-9.

17. Dobiasova M. Atherogenic index of plasma (log (triglycerides/HDLcholesterol): Theoretical and practical implications. Clin Chem. 2004;50(7): 11135.

18. Panimathi R. Rekha K, Geetha K. Total cholesterol/HDL Rasio - and individual predictor of atheroselerosis in acute coronary syndrome. Sch G App Med Sci. 2017;5(8C):3204-8.

19. Hameed IK, Abed BA, Rashid NF. Glycated haemoglobin as a dual marker associated between $\mathrm{HbA1c}$ and dyslipidaemia in type 2 diabetic patients. J Fac Med Baghdad. 2012;54:88-92.
20. Sirsikar M, Supriya, Mohanty S, Pinnelli VBK. Role of glycated hemoglobin (HBA1c) as a dual marker to predict glycemic status and dyslipidemia in type II diabetes mellitus. Int J Res Med Sci 2016;4:4524-9.

21. Mahato RV, Gyawali P, Raut PP, Regmi $P$, Singh KP, Pandeya DR, et al. Asociated between glycemic control and serum lipid Profile in type 2 diabetic patients: Glycated hemoglobin as a dual biomarker. Biomedical research. 2011; 22(3): 375-80.

22. Jeorge Dimitriadis, Panayota Mitrou, Vaia Lambadairi, Eirini Maratou \& Sotirios A Raptis. Insulin effects in mussel and adipose tissue. Diabetes Res. Clin. Pract. 2011,93 (Suppl. 1),552-59

23. Sirsikar M, Supriya, Mohanty S, Pinnelli VBK. Role of glycated hemoglobin (HBA1c) as a dual marker to predict glycemic status and dyslipidemia in type II diabetes mellitus. Int $\mathrm{J}$ Res Med Sci 2016;4:4524-9.

24. Campbell RK. Type 2 diabetes: Where we are today: An overview of disease burden, current treatments, and treatment strategies. J Am Pharm Assoc. 2009;49 (Suppl 1):S3-9.

25. Samman, S. Zinc. Nutr. Diet. 2007, 64, S131-S134.

26. Anderson RA, Roussel AM, Zouari N, Mahjoub S, Matheau JM, Kerkeni A. Potential antioxidant effects of zinc and chromium supplementation in people with type 2 diabetes mellitus. J Am Coll Nutr 2001; 20:212-8.

27. Tripathy S, Sumathi S, Bhupal Raj G. Minerals nutritional status of type 2 diabetic subjects. Int $\mathbf{J}$ Diabetes Dev Ctries 2004; 24:27-8.

28. Saharia GK, Goswami RK. Evaluation of serum zinc status and glycated haemoglobin of type 2 diabetes mellitus patients in a tertiary care hospital of Assam. J Lab Physicians 2013; 5:30-3.

29. Hyun-Mee Ooh, Jin-Sook Yoon.Glycemic control of type 2 diabetic patients after short term zinc supplementation. Nutrition Research and Practice 208,2(4)283-288

30. Saha-Roy, Pal S, Bera S, Choudhury K, Bhattacharya A, Sen G, et al. Status of 
Aman James et.al. Plasma zinc levels, lipid profile parameters and CVD risk markers in relation to glycemic status in T2 DM patients.

serum magnesium, zinc \& copper in patients suffering from type-2 diabetes mellitus. J Drug Deliv Ther 2014; 4:70-2.

31. Masood N, Baloch GH, Ghori RA, Memon IA, Memon MA, Memon MS. Serum zinc and magnesium in type-2 diabetic patients. J Coll Physicians Surg Pak 2009; 19:483-6.

32. Al-Maroof RA, Al-Sharbatti SS. Serum zinc levels in diabetic patients and effect of zinc supplementation on glycemic control of type 2 diabetics. Saudi Med J 2006; 27:344-50.

How to cite this article: James A, Nagendra S, Telang L et.al. Plasma zinc levels, lipid profile parameters and CVD risk markers in relation to glycemic status in T2 DM patients. Gal Int $J$ Health Sci Res. 2021; 6(3): 90-97. DOI: https://doi.org/10.52403/gijhsr.20210714 